\title{
Relapsed Childhood Acute Lymphoblastic Leukemia: A Single-Institution Experience
}

Pham Nguyen Tuong ${ }^{1}$, Tran Kiem Hao ${ }^{2}$, Nguyen Thi Kim Hoa ${ }^{2}$

1. Oncology, Hue Central Hospital, Hue, VNM 2. Pediatrics, Hue Central Hospital, Hue, VNM

Corresponding author: Nguyen Thi Kim Hoa, kimhoa.fmi@gmail.com

\section{Abstract}

\section{Background}

Even though the treatment outcomes of childhood acute lymphoblastic leukemia (ALL) have improved recently, relapse of the disease still remains a challenge in developing countries. This study aims to analyze the incidence of relapse and survival rates in childhood ALL.

\section{Methods}

A retrospective study of 156 children with de novo ALL between 2012-2018 was conducted. Data on age, gender, relapse type, and relapse time were analyzed.

\section{Results}

A total of 26 (16.7\%) patients experienced relapse, with a male-to-female ratio of 2.71:1. The relapse rate in the high-risk group was 1.6 times greater than that in the standard-risk group ( $61.5 \%$ vs. $38.5 \%)$. The median time from diagnosis to relapse was 29.3 months ( $38.5 \%$ in the early stage, $26.9 \%$ in the intermediate, and $34.6 \%$ in the late stage). The most common relapse site was bone marrow (38.5\%), followed by the isolated central nervous system (CNS, 23.1\%) and CNS plus bone marrow (23.1\%); the least common site was testicle with or without bone marrow or CNS (15.2\%). The median post-relapse survival time was 7.5 months.

\section{Conclusion}

Modification of the protocol to use escalated methotrexate dose and providing new therapies such as stem cell transplantation can improve the overall survival rates in relapsed ALL patients.

Received 04/22/2020

Review began $07 / 06 / 2020$ Review ended 07/07/2020 Published 07/17/2020

\section{() Copyright 2020}

Tuong et al. This is an open access article distributed under the terms of the Creative Commons Attribution License CC-BY 4.0., which permits unrestricted use, distribution, and reproduction in any medium, provided the original author and source are credited.
Categories: Pediatrics, Oncology

Keywords: relapse, acute lymphoblastic leukemia, treatment

\section{Introduction}

Acute lymphoblastic leukemia (ALL) is the most common malignant disease in children. It accounts for onefourth of all childhood cancers and $72 \%$ of all cases of childhood leukemia. Its incidence is estimated to be two to five per 100,000 children. The peak incidence of ALL occurs between the ages of two to five. With the recent advances in chemotherapy, hematopoietic stem cell transplant, and supportive care, the long-term survival in childhood ALL has increased to $85-90 \%$. The most important prognostic factors for determining post-relapse survival rate are relapse site (bone marrow, isolated extramedullary), the timing of relapse (early or late), and the phenotype of the disease [1-3].

Hue Central Hospital, one of the three biggest hospitals with 3,000 beds in Vietnam, plays a vital role in treating childhood ALL in the central region of Vietnam. Since 2008, ALL patients have been treated based on the Children's Cancer Group's (CCG) modified 1882 and 1881 protocols. We carried out this research to analyze the incidence of relapse and survival rate in childhood ALL treated at Hue Central Hospital between January 2012 and April 2018. We believe our findings will contribute to further improving the treatment outcomes in children with ALL.

\section{Materials And Methods}

We reviewed the medical records of 156 new patients who were under 16 years of age and diagnosed with ALL. These patients were registered at Hue Pediatric Center, Hue Central Hospital, from January 1, 2012, to April 30, 2018. All patients had received the same treatment as per the modified CCG 1882 and 1881 protocols (Tables 1,2). 


\section{Cureus}

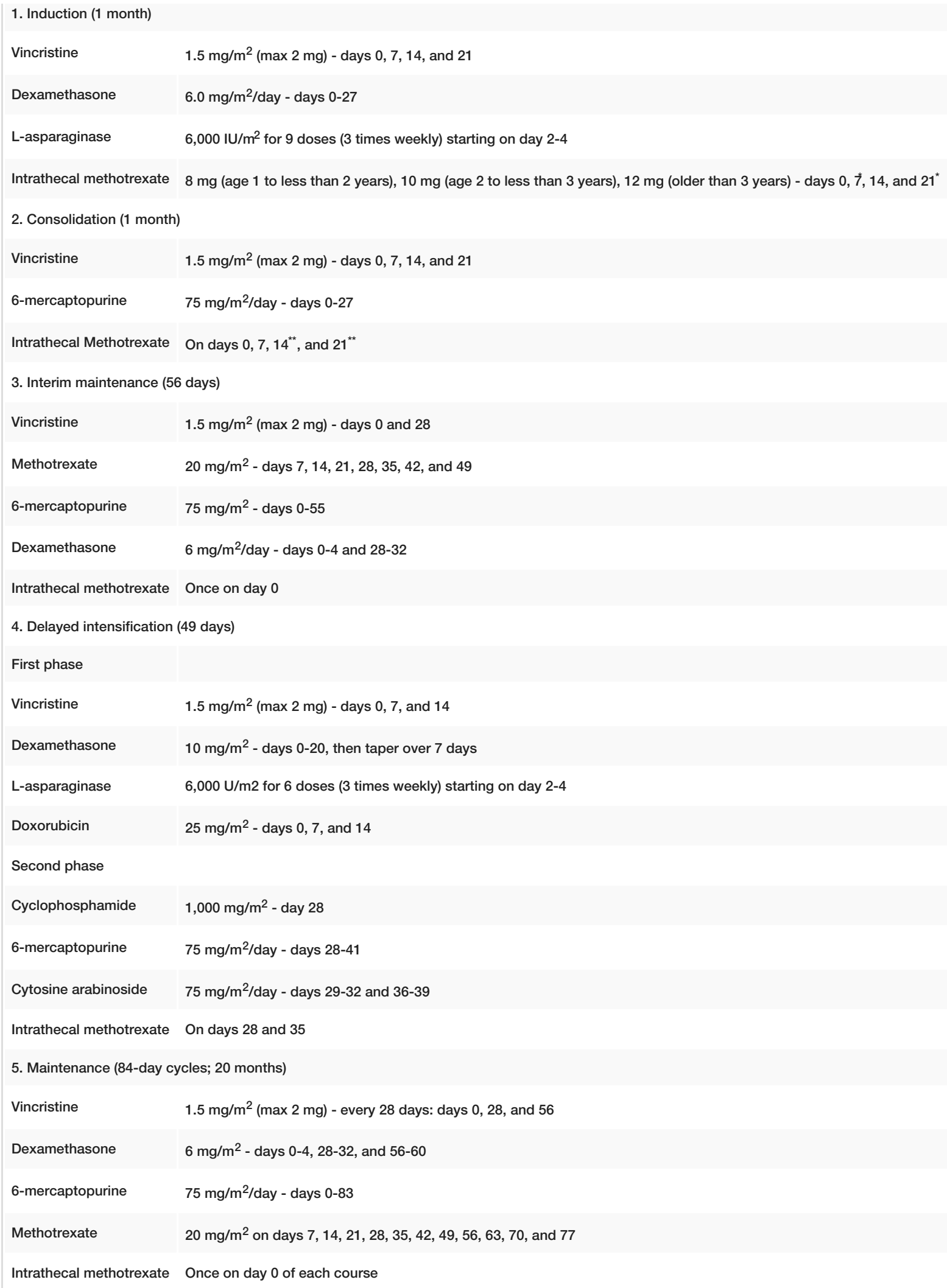

TABLE 1: Treatment regimen for standard-risk ALL (modified CCG-1881)

*Patients with central nervous system disease at diagnosis only; **Patients without central nervous system disease at diagnosis will not receive intrathecal therapy on days 14 and 21

ALL: acute lymphoblastic leukemia; CCG: Children's Cancer Group 


\section{Cureus}

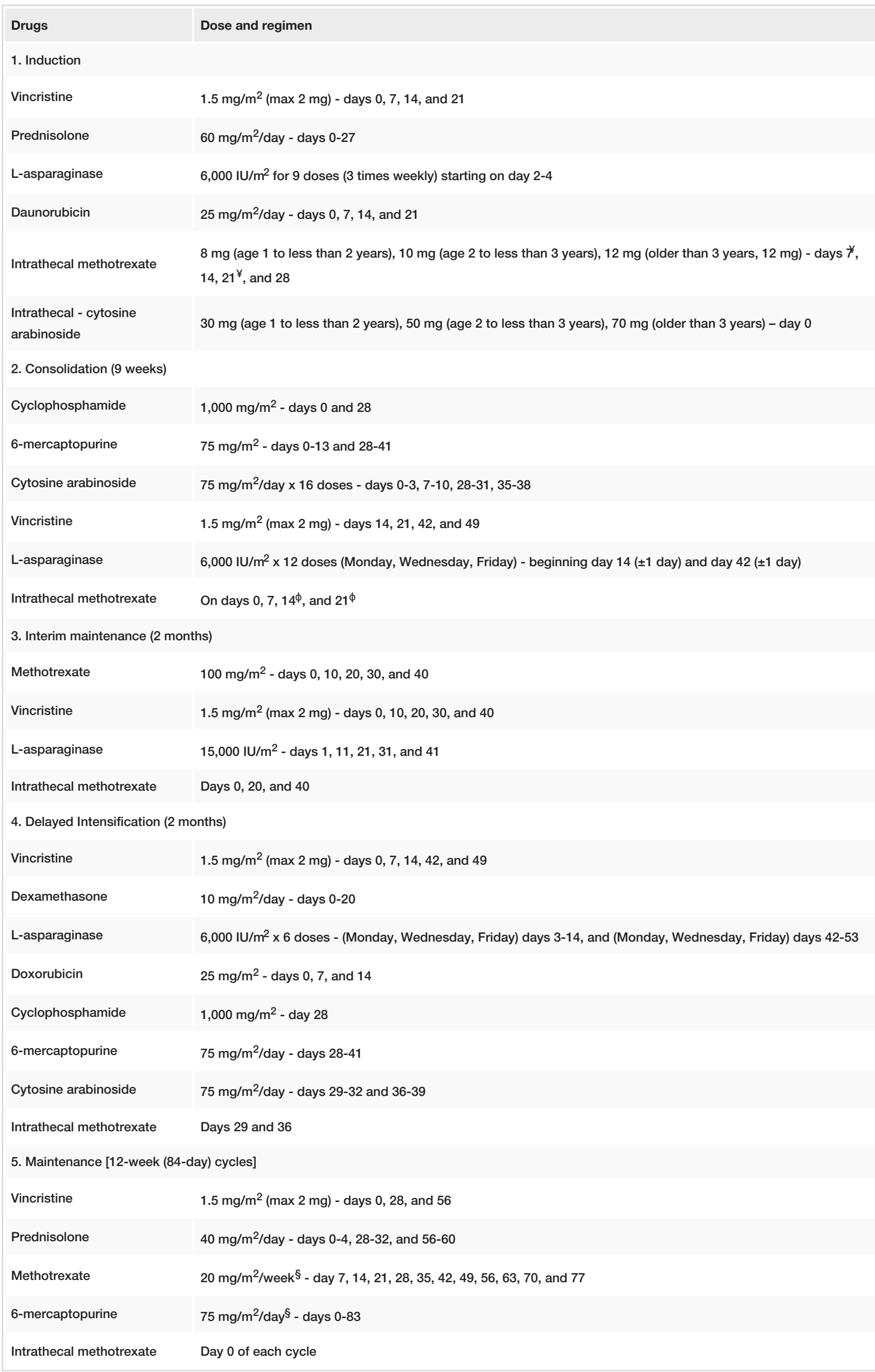




\section{Cureus}

TABLE 2: Treatment regimen for higher-risk ALL (modified CCG-1882)

${ }^{¥}$ Patients with CNS disease at diagnosis only; P Patient without CNS disease at diagnosis will not receive intrathecal therapy on days 14 and 21 ; §Doses escalated for ANC of $>2,000$ and platelet count of $\geq 100,000$

ALL: acute lymphoblastic leukemia; CCG: Children's Cancer Group; CNS: central nervous system; ANC: absolute neutrophil count

Diagnosis of ALL at presentation was based on the results of bone marrow morphology, where the leukemic blasts were counted for more than $25 \%$ in the marrow space. Relapse time was categorized as early, intermediate, and late-stage according to the time from initial diagnosis of $<18$ months, $18-36$ months, and $\geqslant 36$ months, respectively.

All data were analyzed according to age, gender, relapse timing, relapse period, and relapse site using SPSS Statistics version 20 (IBM, Armonk, NY). Measurement data were described by rate or proportion, and enumeration data were described by means and standard deviations. The Kaplan-Meier method was used for generating survival curves for overall survival. A log-rank test was performed for comparing survival across groups.

\section{Results}

Data relating to 156 new patients with ALL between 2012 to 2018 were collected. Among them, there were 26 relapses, accounting for $16.7 \%$ of the total cases. The male-to-female ratio was $2.71: 1$. The relapse rate in the high-risk group was 1.6 times greater than that in the standard-risk group (61.5\% vs. $38.5 \%)$; $85.5 \%$ of patients achieved remission after the induction phase (Table 3).

\begin{tabular}{|l|l}
\hline Characteristics & N (\%) \\
\hline Gender & 19 (73.1) \\
Male & (26.9) \\
Remale & 10 (38.5) \\
Standard group classification, $n$ (\%) & 16 (61.5) \\
High & 23 (88.5) \\
Achieved remission after the induction phase & $3(11.5)$ \\
Yes & \\
No &
\end{tabular}

\section{TABLE 3: Baseline characteristics of children with relapsed ALL $(n=26)$}

The median time from diagnosis to relapse was $29.3 \pm 18.2$ months, of which $38.5 \%$ of cases occurred in the early stage, $26.9 \%$ in the intermediate, and $34.6 \%$ in the late stage. Fourteen (53.8\%), six (23.1\%), four (15.4\%), and two (7.7\%) cases relapsed during the maintenance phase, after completing chemotherapy, at delayed intensification phase, and after induction phase (due to treatment abandonment), respectively. The most common relapse site was bone marrow (38.5\%), followed by the isolated central nervous system (CNS, $23.1 \%$ ), and CNS plus bone marrow (23.1\%); the least common site was testicle with or without bone marrow or CNS (15.2\%). The median post-relapse survival time was $7.5 \pm 8.3$ months, and the three-year post-relapse overall survival rate was $26.9 \%$ (Table 4). Patients with intermediate relapse had a better survival rate than those with early relapse and late relapse (Figure 1). 


\section{Cureus}

Characteristics

Relapse timing, n (\%)

Early relapse

Intermediate relapse

Late relapse

Median time to relapse (months)

Relapse period, $\mathrm{n}(\%)$

Maintenance phase

Finished treatment

Delayed intensification II

Consolidation refused

Relapse site, $\mathrm{n}(\%)$

Bone marrow

Central nervous system

Bone marrow + central nervous system

Testicle

Testicle + bone marrow

Testicle + central nervous system

Post-relapse survival

3-year overall survival rate (\%)

Median survival time (months)
Value

$10(38.5)$

7 (26.9)

9 (34.6)

$29.3 \pm 18.2$

$14(53.8)$

$6(23.1)$

4 (15.4)

$2(7.7)$

10 (38.5)

$6(23.1)$

$6(23.1)$

2 (7.6)

1 (3.8)

1 (3.8)

26.9

$7.5 \pm 8.3$

TABLE 4: Characteristics of relapsed patients $(n=26)$

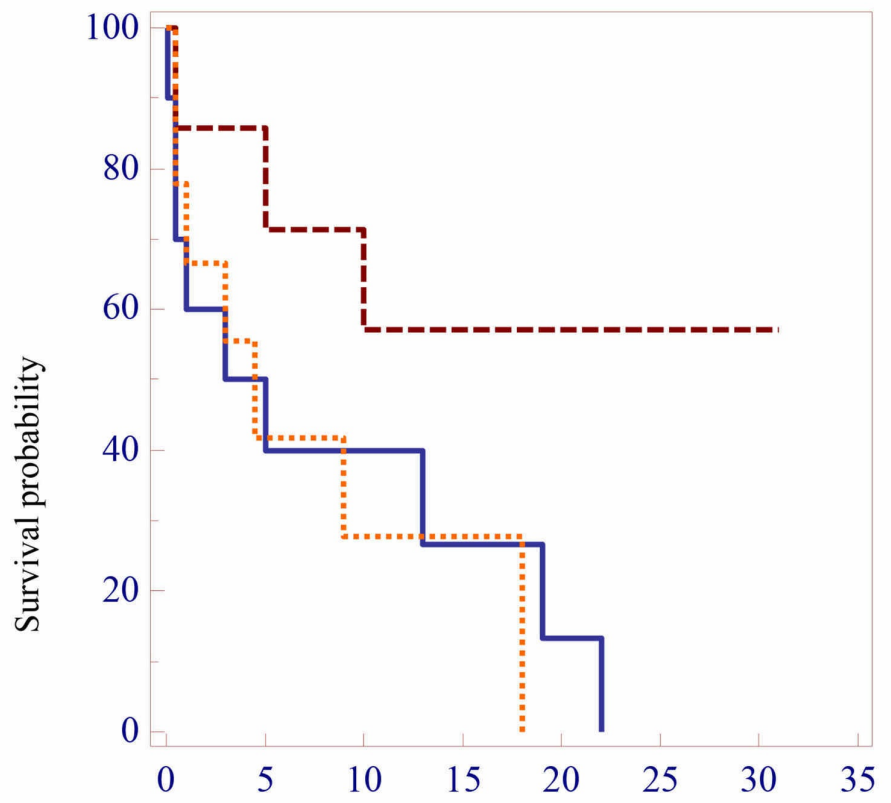

Relapse events

- $<18$ months

-ー- 18-36 months

..... $\geq 36$ months 


\section{Discussion}

Our study showed a relapse rate of $16.7 \%$, which is higher compared to findings of studies by Locatelli et al. and Oskarsson et al. [3,4], but lower than in studies by Ali et al. and Nguyen et al., which reported relapse rates of $24.5 \%$ and $20.5 \%$, respectively $[5,6]$. The male-to-female ratio $(2.7: 1)$ in this study was similar to some other studies where the relapse rate was higher among males than females; based on these studies, males carry a distinctly poor prognosis factor while females have a better prognosis than males $[7,8]$. We also noted that the relapse rate in the high-risk group was 1.6 times greater than that in the standard-risk group (61.5\% vs. 38.5\%). This result was mostly consistent with other studies $[6,7]$.

Among the relapsed cases, three patients (11.5\%) did not achieve remission, which was similar to findings by Pizzo and Poplack, which showed that an early response to induction therapy has prognostic value [7]. Regarding the relapse period $(53.8 \%, 23.1 \%$, and $15.4 \%$ relapsed during the maintenance phase, after finishing therapy, and delayed intensification II phase, respectively), our results were similar to those of Ali et al., which reported $59.9 \%$ of relapsed cases during the maintenance phase [5].

Regarding the relapse site, bone marrow was the leading site and accounted for $38.5 \%$, while the testicle had the lowest rate of relapse (15.3\%). Again, these results were similar to the outcomes of Ali et al. and Pizzo and Poplack [7]. The reason for the relatively higher testicle relapse in our study compared to another study could be attributed to our protocol, which was not strong enough to eradicate ALL cells in testicle [9].

At the endpoint (April 2018), $73.1 \%$ of relapse patients had passed away while $26.9 \%$ of patients were still alive. The median time from relapse to death was $7.5 \pm 8.3$ months, which was shorter compared to other studies. It might be due to the protocol we used. The protocol was not strong enough and was lacking in some tests, such as minimal residual disease to evaluate the response. According to Nguyen et al., overall post-relapse survival rates were higher for patients with isolated CNS relapse $(58.7 \pm 3.2 \%)$ than for patients with either isolated $(24.1 \pm 2.1 \%$ ) or concurrent bone marrow (39.4\% $\pm 5.0 \%$ ) relapses [6].

Regarding the correlation between relapse events and survival after relapse, patients with intermediate relapse had a better survival rate than early relapse (Figure 3). This result appears reasonable. Time to relapse remains the strongest predictor of survival. According to Nguyen et al., estimates of five-years survival rates for isolated marrow relapse in early-, intermediate-, and late-relapsing patients were $11.5 \pm 1.9$, $18.4 \pm 3.1$, and $43.5 \pm 5.2 \%$, respectively [6]. Van De Berg et al. also showed similar results regarding five-year event-free survival rates for early and late relapses: $12 \%$ and $35 \%$, respectively [10].

Recently, several studies have suggested that modification of the protocol to use escalated methotrexate dose and providing new therapies such as stem cell transplantation can improve the overall survival of relapsed patients $[11,12]$.

\section{Conclusions}

In our study, we found that most relapse events in ALL occurred during the maintenance phase and after the completion of chemotherapy. Bone marrow and CNS were the most common relapse sites. According to several recent studies, modification of the protocol to use escalated methotrexate dose and providing new therapies such as stem cell transplantation can improve the overall survival rates in childhood ALL.

\section{Additional Information \\ Disclosures}

Human subjects: Consent was obtained by all participants in this study. Hue Central Hospital Research Ethics Committee issued approval 01012019-HCH. This study was approved by the Hue Central Hospital Research Ethics Committee. Animal subjects: All authors have confirmed that this study did not involve animal subjects or tissue. Conflicts of interest: In compliance with the ICMJE uniform disclosure form, all authors declare the following: Payment/services info: All authors have declared that no financial support was received from any organization for the submitted work. Financial relationships: All authors have declared that they have no financial relationships at present or within the previous three years with any organizations that might have an interest in the submitted work. Other relationships: All authors have declared that there are no other relationships or activities that could appear to have influenced the submitted work.

\section{References}

1. Goto H: Childhood relapsed acute lymphoblastic leukemia: biology and recent treatment progress . Pediatr 
Int. 2015, 57:1059-66. 10.1111/ped.12837

2. Henderson MJ, Choi S, Beesley AH, et al.: Mechanism of relapse in pediatric acute lymphoblastic leukemia . Cell Cycle. 2008, 7:1315-20. 10.4161/cc.7.10.5885

3. Locatelli F, Schrappe M, Bernardo ME, Rutella S: How I treat relapsed childhood acute lymphoblastic leukemia. Blood. 2012, 120:2807-16. 10.1182/blood-2012-02-265884

4. Oskarsson T, Söderhäll S, Arvidson J, et al.: Relapsed childhood acute lymphoblastic leukemia in the Nordic countries: prognostic factors, treatment and outcome. Haematologica. 2016, 101:68-76. 10.3324/haematol.2015.131680

5. Ali K, Sutaryo S, Purwanto I, et al.: Yogyakarta Pediatric Cancer Registry: an international collaborative project of University Gadjah Mada, University of Saskatchewan, and the Saskatchewan Cancer Agency. Asian Pac J Cancer Prev. 2010, 11:131-6.

6. Nguyen K, Devidas M, Cheng SC, et al.: Factors influencing survival after relapse from acute lymphoblastic leukemia: a Children's Oncology Group study. Leukemia. 2008, 22:2142-50. 10.1038/leu.2008.251

7. Pizzo PA, Poplack DG: Principles and Practices of Pediatrics Oncology. Lippincott Williams \& Wilkins, Philadephia, PA; 2016.

8. Slats AM, Egeler RM, van der Does-van den Berg A, et al.: Causes of death--other than progressive leukemia--in childhood acute lymphoblastic (ALL) and myeloid leukemia (AML): the Dutch Childhood Oncology Group experience. Leukemia. 2005, 19:537-44. 10.1038/sj.leu.2403665

9. Ortega JJ, Javier G, Torán N: Testicular infiltrates in children with acute lymphoblastic leukemia: a prospective study. Med Pediatr Oncol. 1984, 12:386-93. 10.1002/mpo.2950120606

10. van den Berg H, de Groot-Kruseman HA, Damen-Korbijn CM, de Bont ES, Schouten-van Meeteren AY, Hoogerbrugge PM: Outcome after first relapse in children with acute lymphoblastic leukemia: a report based on the Dutch Childhood Oncology Group (DCOG) relapse all 98 protocol. Pediatr Blood Cancer. 2011, 57:210-6. 10.1002/pbc.22946

11. Chessells JM, Veys P, Kempski H, Henley P, Leiper A, Webb D, Hann IM: Long-term follow-up of relapsed childhood acute lymphoblastic leukaemia. Br J Haematol. 2003, 123:396-405. 10.1046/j.13652141.2003.04584.x

12. Locatelli F, Zecca M, Messina C, et al.: Improvement over time in outcome for children with acute lymphoblastic leukemia in second remission given hematopoietic stem cell transplantation from unrelated donors. Leukemia. 2002, 16:2228-37. 10.1038/sj.leu.2402690 